\title{
Congenital pouch colon: review of current clinical and molecular studies
}

\begin{abstract}
Congenital Pouch Colon $[\mathrm{CPC}]$ is a condition in which whole or part of the colon is replaced by a pouch like dilatation and communicates with urogenital tract through a fistula. It is a variant of Anorectal Malformation [ARM]. CPC differs from normal colon both structurally and functionally. It is a common congenital anomaly in the Indian Subcontinent. The literature is replete with the clinical and histopathology studies of CPC. However there is paucity of molecular studies. The present review provides the insight of current trends in management and molecular research of CPC.
\end{abstract}

Keywords: anorectal malformations, congenital pouch colon, molecular basis
Volume 5 Issue 9 - 2016

\author{
Maudar KK,' Gandhi P,I Varshney S,' \\ Budhwani KS, ${ }^{2}$ Ghritalaharery RK ${ }^{2}$ \\ 'Department of Surgical Gatroenterology, Bhopal Memorial \\ Hospital and Research Centre [BMHRC], India \\ 2Department of Pediatric Surgery, Gandhi Medical College, India \\ Correspondence: Maudar KK, Department of Surgical \\ Gatroenterology, Bhopal Memorial Hospital and Research \\ Centre [BMHRC], Bhopal, India, Email maudarji@yahoo.com
}

Received: October 30, 2016 | Published: December 30, 2016

Abbreviations: HMGA, high mobility group A; Wnt, W+Int it is derived from 2 members Wingless larva of drosophila and mouse; GLi, glioma- associated oncogene family of zinc finger; HES1, helix loop of transcriptional factor; hTERT, human telomerase reverse transcriptase

\section{Introduction}

Congenial Pouch Colon (CPC) is a variant of ARM. The incidence of $\mathrm{CC}$ has been reported to be $8 \%-20 \%$. from India as compared to other parts of the world. Intrauterine vascular accidents, obliteration of inferior mesenteric artery or part of it and factors like pesticides, geographic environment, climate, economic and cultural status, are believed to be factors responsible for ARM. However, recent reports in the literature have shown that the germ line mutations/ deletions of genes encoding the proteins of the signaling pathways responsible for normal colon result in its malformations in experimental studies. ${ }^{1-6}$

\section{Classification of CPC}

There are 4 types of CPC.

Type I: Normal colon is absent and the ileum opens directly into the pouch.

Type II: The ileum opens into a short segment of caecum which then opens into the pouch.

Type III: Presence of a significant length of normal colon between the ileum and the colonic pouch..

Type IV: Presence of near normal colon with only the terminal portion of the colon [sigmoid and rectum] converted into a pouch.

Type I and Type II are commonest with 90\% incidence $\mathrm{CPC}$ is considered to be high type of Anorectal anomaly and in the international classification [Krickenbeck-2005] it is considered under the Rare/Regional variant group of ARM.

Etiology: Environmental factors, nutritional factors,-Iodine and vitamin B deficiency, pesticides and poor socioeconomic status. Since inferior mesenteric vessels were reported to be absent in some cases of CPC vascular insult during embryogenesis was an accepted mechanism of etiopathogenesis of CPC.
Gross pathological characteristics of CPC: Distal colonic globular swelling which is thick, with abnormal vasculature, no taenia, coli or epiploicae, no haustrations and fistulous communication with the urinary bladder/genital tract.

Histopathology: The presence of an unusual additional muscle layer in between the submucosa and inner circular muscle layer with variable thinning of the outer longitudinal muscle layer and decussating circular muscle fibres. The submucosa shows several lymphoid aggregates with some active germinating centres, and chronic non-inflammatory and inflammatory cell infiltrate. Neuronal hyperplasia, nerve bundle hypertrophy, normal nerve fibres, normal ganglion cells, giant ganglion cells with uneven distribution, ectopic heteroplastic tissues are seen. Fibrosis is present in all layers of muscles and unique constriction bands in muscularis propria..$^{7-10}$

Management: Diagnosis is usually made during the investigation of ARM and confirmed by colography. In the newborns it is advised to do colostomy/ileostomy and leave the pouch and avoid window colostomy in the pouch. Definitive treatment includes excision of the pouch and pull through of normal segment of the colon or coloplasty and fistula is disconnected. The operative procedures can be carried out in single stage, two or three staged procedures. The Indian literature is replete with the different surgical techniques. Since CPC was first reported by Professor IC Pathak in $1972^{1}$ there are large series of CPC with reviews and evaluations of various surgical procedures. ${ }^{11-14}$

\section{Molecular research}

\section{Embryogenesis of normal colon}

Embryonic gut tube forms Anterior Intestinal Portal [AIP] and Caudal Intestinal Portal [CIP] and two tissues endoderm \& splanchnic mesoderm. Foregut is derived from AIP, Midgut from both AIP \& CIP and Hind gut from CIP. Endoderm and Splanchnic Mesoderm differentiate into various tissues and create organs. The entire process of development is guided by "Cross Talk" by the 'SignalingWeb'. The current knowledge of signaling Web for the development of gastrointestinal tract is based on the genetics of Drosophila and mouse model $^{6}$

The following signaling genes take part in the formation "Transcriptional Cycle" 
I. Wnt gene with its 19 signaling molecules,10 Fizzled surface receptors, and Beta catenin transcriptor

II. Hedgehog [HH] signaling genes namely Sonic Hh, Indian Hh \& Desert Hh. Patched Proteins [PTCH] receptor and GLi2 \& GLi3 transcriptors are for Hh genes signal pathways.

\section{NOTCH signaling gene and its transcriptor HMGA1. ${ }^{15-17}$}

Hedgehog Gene [Hh] was named as Hedgehog because of stubby and hairy body of larva of Drosophila. Wingless protein was called wingless because of wingless fly mutant. Wnt gene was derived from wingless-Drosophila $-\mathrm{W}$ and int-mouse-nt. Wnt is a family of cell -to cell signaling proteins. Reciprocal signaling by Wnt and Hh stabilises binding and establishes anatomical feature along the AIP axis. Deletion of genes/germ-line mutation encoding $\mathrm{Hh}$ signaling pathways can cause ARM, Malrotation of gut and other gastrointestinal malformations.

Indian Hedgehog gene [Ihh] and Sonic Hedgehog [Shh] mutation in mouse model also results in abnormal innervation, reduced smooth muscles, stenosis and malrotation of the gut. ${ }^{18}$

NOTCH signaling pathways: John Dextor [1914] noticed Notch in the wings of fruit fly Drosophila and Morgan [1917] identified a dominant gene in Drosophila which caused irregular tissue loss causing notches at the tips of wing blades NOTCH gene in Drosophila. $\mathrm{NOTCH}$ pathways participate in Neuron cell development and differentiation and intestinal development. ${ }^{19}$

$\mathrm{NOTCH}$, Wnt and Hh signaling pathways are linked with transcriptional regulators hTERT and HMGA1and form an Interlink Circle Web. Any disturbance in one or more links leads to deregulation of the signaling web resulting into multiple malformations. ${ }^{20}$ The VACTERAL association [Vertebral defects, Anal defects, Cardiac defects, Tracheo-esophaeal fistula, Renal abnormalities and Limb abnormalities], ARM and neuro musculature abnormalities are explained on Hh signaling pathways. $^{21}$

\section{Conclusion}

Molecules from the three embryonic signaling pathways Wnt, $\mathrm{NOTCH}$ and Hedgehog were expressed in CPC. Expression of HMGA1 indicates that it transduces WNt signals as the beta catenin levels rise. Beta catenin is the main molecule capable of regulating Wnt, NOTCH and Hedgehog pathways.

More biochemical and molecular studies of various types of gastrointestinal malformations will provide a better insight into the varied mechanistic and their key turn-points during development of Gastrointestinal tract.

\section{Acknowledgements}

None.

\section{Conflict of interest}

The authors declare no conflict of interest.

\section{Funding}

None.

\section{References}

1. Singh S, Pathak IC. Short colon associated with imperforate anus Surgery. 1972;71(5):781-786.
2. Chiba T, Kasai M, Asakura Y. Two cases of coloplasty for congenital short colon. Nihon Geka Hokan. 1976;45(1):40-44

3. Narasimharao KL, Yadav K, Mitra SK, et al. Congenital Short Colon with Imperfonate Anus Pouch Colon Syndrom. Annals of Paediatric Surgery. 1984;1:159-167.

4. Wakhlu A, Wakhlu AK. Technique and long term results of coloplasty for Congental Short Colon. Pediatr Surg Int. 2009;25:47-52.

5. Nicole AT, Clifford JT. Wnt signaling during development of the gastrointestinal tract. Development Biology. 2003;259(2):258-271.

6. Roberts D. Molecular mechanisms of development of the gastrointestinal tract. Dev Dyn. 2006;219:1009-1020.

7. Agarwal K, Chadha R, Ahluwalia C, et al. The Histopathology of congenital pouch colon associated with anorectal agenesis. Eur $J$ Pediatric Surg. 2005;15(2):102-106.

8. Gupta DK, Sharma S. Congenital Pouch colon. Then and now J Indian Assoc Peditric Surg. 2007;12(1):5-12.

9. Pavai A, Pillai SD, Shanthakumari S, et al. Congenital Pouch Colon. Increasing association with low anorectal anomalie. J Indian Assoc Peadiatr Surg. 2009;14(4):218-220.

10. Dhiraj BK, Kishore S, Sudhir S, et al. Congenital Pouch Colon :A rare variant of Anorectal malformations:Histopathological perspective with brief review of literature. J Interdiscipl Histopathology. 2014;2:173178.

11. Ganagopadhyaya AN, Patne SC, Pandey A, et al. Congenital Pouch Colon associated with anorectal malformation-histopathological evaluation. J Paediatr Surg. 2009;44(3):600-606.

12. Puri A, Choudhury SR, Yadav PS, et al. Congenital Pouch Colon and segmental dilatation of the colon:A report of two unusual cases. J Indian Assoc of Pediatr Surg. 2011;16(2):61-63.

13. Sharma S, Gupta DK, Bajpai M, et al. Management of congenital Pouch Colon in association with ARM. J Indian Assoc Pediatr Surg. 2005; 10:s22.

14. Panda SS, Bajpai M, Singh A, et al. Effects of Surgical techniques on long- term outcome in congenital pouch colon:A tertiary care centre experience Afr J Paediatr Surg. 2014;11(3):248-251.

15. Hulsken J, Behrens J. The Wnt signaling pathways. J Cell Sci. 2007; 113:35-45.

16. Tai CC1, Sala FG, Ford HR, et al. Wnt 5a Knock-out Mouse as a new model of Anorectal Malformation J Surg Res. 2009;156(2):278-282.

17. Fairbanks TJ, Kanard RC, Del Moral PM, et al. Colonic Atresia without mesenteric vascular occlusion. The role of the fibroblast growth factor10 signaling pathway. J Pediatr Surg. 2005;40(2):390-396.

18. Lees C, Howie S, Sartor RB, et al. The Hedgehog Signaling in the Gastrointestinal Tract. Implications for Development, Homeostasis and Disease. Gastroenterology. 2005;129(5):1696-1710.

19. Ramalho-Santos M, Melton DA, McMahon AP. Hedgehog signals regulate multiple aspects of gastro intestinal development. Development. 2000;127(12):2763-2772.

20. Kim TH1, Kim BM, Mao J, et al. Endodermal Hedghehog signals modulate NOTCH pathway in the Digestive tract Mesenchymal. Development. 2011;138(15):3225-3233.

21. Kim J, Kim P, Hui CC. The VACTERAL association Lessons from Sonic hedgehog pathways. Clin Genet. 2001;60:397-398. 